\title{
Follicular lymphoma in situ with coincident low-grade B cell lymphoma: a case series
}

\author{
Winnie Wu • Kate Grimm • Jennifer Hummel • \\ Lawrence Weiss • Keyur Patel • Carlos Bueso-Ramos • \\ Dennis P. O'Malley
}

Received: 20 March 2014 / Accepted: 25 June 2014 / Published online: 15 July 2014

(C) Springer-Verlag Berlin Heidelberg 2014

\begin{abstract}
Follicular lymphoma in situ is a rare, recently described entity. It is defined by the accumulation of $\mathrm{t}(14 ; 18)+$, BCL2 strongly positive clonal B cells restricted to germinal centers in morphologically normal lymph nodes, without alteration of follicle morphology, size or distribution, or perifollicular spread. The presence of a follicular lymphoma in situ has three main clinical ramifications, including the potential coexistence of a simultaneous disseminated follicular lymphoma, risk of subsequent overt follicular lymphoma,
\end{abstract}

\author{
W. Wu \\ David Geffen School of Medicine, UCLA School of Medicine, \\ 10833 Le Conte Ave., 13-145G CHS, Los Angeles, CA 90095-1732, \\ USA \\ e-mail: winniewu@mednet.ucla.edu \\ K. Grimm • J. Hummel • L. Weiss • D. P. O’Malley $(\bowtie)$ \\ Clarient Diagnostic Services, Clarient/GE Healthcare, 31 Columbia, \\ Aliso Viejo, California, CA 92656, USA \\ e-mail: domalley@clarientinc.com \\ K. Grimm \\ e-mail: grimmpathologist@gmail.com \\ J. Hummel \\ e-mail: jhummel@clarientinc.com \\ L. Weiss \\ e-mail:1weiss@clarientinc.com \\ K. Grimm \\ Keck School of Medicine, University of Southern California, Los \\ Angeles, CA, USA \\ K. Patel · C. Bueso-Ramos • D. P. O’Malley \\ M.D. Anderson Cancer Center/University of Texas, Houston \\ University of Texas, Box 72, Houston, 1515 Holcombe Blvd, Texas, \\ TX 77030, USA \\ K. Patel \\ e-mail: kppatel@mdanderson.org \\ C. Bueso-Ramos \\ e-mail: cbuesora@mdanderson.org
}

and association with a second subtype of lymphoma. We report cases of follicular lymphoma in situ in conjunction with lymphoplasmacytic lymphoma (two cases) and mantle cell lymphoma (one case). Each case was evaluated, and diagnoses confirmed using a combination of histologic, immunohistochemical, fluorescence in situ hybridization (FISH), and molecular techniques. One case of lymphoplasmacytic lymphoma was proven positive for myeloid differentiation primary response 88 gene (MYD88) mutation. Our series expands the current literature of this rare phenomenon. We discuss possible etiologies and clinical impact of follicular lymphoma in situ.

Keywords Follicular lymphoma in situ $\cdot$ Mantle cell lymphoma $\cdot$ Lymphoplasmacytic lymphoma $\cdot$ MYD88

\section{Introduction}

Follicular lymphoma in situ (FLIS) is a relatively recently described clinicopathologic entity[1].[1,2] It is defined by the accumulation of $t(14 ; 18)+$, BCL2 strongly positive clonal $\mathrm{B}$ cells restricted to germinal centers in morphologically normal lymph nodes, without alteration of follicle morphology, size, or distribution and without perifollicular spread. By definition, FLIS usually is detected by immunostaining only, and cases which are suspicious by morphology often represent follicular lymphoma (FL) with partial nodal involvement.

The presence of a FLIS has three main clinical ramifications, including the potential coexistence of a simultaneous disseminated FL, risk of subsequent overt FL, and association with a second subtype of lymphoma. Large series of FLIS have reported the incidence of a simultaneous disseminated FL in $18-23 \%$ of cases and the development of subsequent overt FL in $3-12 \%$ of cases, with a time to progression ranging from 3 to 72 months $[3,4,11]$. It has been shown 
that in $85-100 \%$ of cases, the cells of FLIS have the translocation of the $I G H / B C L 2$ genes [e.g., $\mathrm{t}(14 ; 18)]$ [11]. However, they likely lack the subsequent molecular or genetic "hits" to develop into overt lymphoma. It has also been shown that a significant percentage $(66 \%)$ of adults harbor very small numbers ( 1 in $\left.10^{5}\right)$ of circulating B cells with an IGH/BCL2 translocation [12, 14-18]. Growing data from comparative genetic analyses increasingly suggest that the differences between subclinical, rare circulating cells with IGH/BCL2 translocation, FLIS, and systemic FL have to do with accumulating additional molecular/genetic abnormalities which lead to disease progression [20, 26]. Follicular lymphoma in situ has been shown to rarely recur and may occasionally involve more than one site (Table 1).

Follicular lymphoma in situ is typically identified by pathologic examination of lymph nodes. These may be removed incidentally for other procedures or have isolated lymphadenopathy. FLIS have the morphologic features of normal germinal centers or reactive follicular hyperplasia. However, the cells have the immunophenotypic and genotypic features of follicular lymphoma. Most cases are identified by staining for BCL2 protein in lymph nodes. In these cases, the abnormal B cells within follicles stain strongly for BCL2 protein, in contrast to normal germinal center $\mathrm{B}$ cells which are negative for BCL2 expression. In addition, the abnormal cells of FLIS have characteristic strong staining for BCL2 protein, compared to both mantle zone B cells and germinal center T cells, both of which express BCL2 more weakly. Criteria have been set forth which are useful to distinguish partial lymph node involvement by systemic FL versus FLIS, with the latter distinguished by normal lymph node architecture, normalsized follicles, intact mantle zones with a sharp demarcation from the germinal center, and a pure population of centrocytes which are confined to the germinal center [11, 21, 22]. However, for appropriate clinical management, any cases of

Table 1 Lymphomas associated with follicular lymphoma in situ

\begin{tabular}{lll}
\hline Lymphoma type & $\begin{array}{l}\text { No. of } \\
\text { cases }\end{array}$ & Reference \\
\hline $\begin{array}{l}\text { Chronic lymphocytic leukemia/small } \\
\text { lymphocytic lymphoma }\end{array}$ & 3 & {$[3,11,28]$} \\
$\begin{array}{l}\text { Lymphoplasmacytic lymphoma } \\
\text { Nodal marginal zone lymphoma }\end{array}$ & 3 & {$[3,11]$, current series } \\
Diffuse large B cell lymphoma & 5 & {$[11]$} \\
Classical Hodgkin lymphoma & 5 & {$[4,28]$} \\
Splenic marginal zone lymphoma & 2 & {$[4]$} \\
Mantle cell lymphoma in situ & 3 & {$[8,23,28]$} \\
Mantle cell lymphoma & 2 & {$[23]$, current series } \\
MALT lymphoma & 1 & {$[28]$} \\
Peripheral T cell lymphoma & 3 & {$[24,28]$} \\
Mycosis fungoides & 1 & {$[28]$} \\
\hline
\end{tabular}

suspected FLIS should have clinical staging to exclude the possibility of minimal or localized involvement by systemic FL.

It has been reported previously that FLIS may found in association with other lymphomas $[3,4,11]$. Cases of concurrent FLIS with chronic lymphocytic leukemia/small lymphocytic lymphoma (three cases) [3, 11, 28], lymphoplasmacytic lymphoma (one case) [3, 11], nodal marginal zone lymphoma (one case) [11], diffuse large B cell lymphoma (five cases) [4, 28], classical Hodgkin lymphoma (five cases) [4, 11, 28], splenic marginal zone lymphoma (two cases) [4], mantle cell lymphoma in situ (three cases) [8, 23, 28], overt mantle cell lymphoma (one case) [23], mucosa-associated lymphoid tissue (MALT) lymphoma (one case) [28], peripheral $\mathrm{T}$ cell lymphoma (three cases) [24, 28], and mycosis fungoides (one case) [28] have been reported.

We report a series of three cases of FLIS concurrent with a second small B cell lymphoma, including two cases of lymphoplasmacytic lymphoma and one case of mantle cell lymphoma in the same lymph node.

\section{Materials and methods}

Cases were obtained from the consultation files of Clarient Diagnostic Services/GE Healthcare (Aliso Viejo, CA). Because of the reference nature of our practice, only minimal clinical information and follow-up was available for review. Histology was reviewed (DPO, LMW, WW) and a panel of immunohistochemical stains was performed using standard methodologies. In each case, a diagnosis was rendered according to the 2008 WHO Classification for Tumors of Hematopoietic and Lymphoid Tissue. Evaluations were performed in accord with institutional guidelines for human research.

Immunohistochemistry

A panel of immunohistochemical stains was performed on all candidate cases in which slides or blocks were available. Depending on the material available, a combination of CD3, CD20, PAX5, CD5, CD10, cyclin D1 (BCL1), BCL2, BCL6, IGG, IGM, IGA, and Ki-67 immunohistochemical stains was performed using standard methodologies.

Fluorescence in situ hybridization

Fluorescence in situ hybridization (FISH) was performed using formalin-fixed, paraffin-embedded tissue sections using a BCL2 dual-color, break-apart probe and an IGH/BCL2 dualcolor, dual-fusion probe in all cases and an $I G H / B C L 1$ (CCND1) dual-color, dual-fusion probe (Abbott Molecular/ Vysis; Abbott Park, IL) in case 3. Germinal centers which 
demonstrated strong BCL2 immunohistochemical staining were identified as FLIS lesions for FISH, while the mantle cell lymphoma lesion was identified for FISH by its strong BCL1 immunohistochemical staining. Fifty interphase nuclei were analyzed for each probe set, and the specimen was considered positive if the number of observed signals was greater than the normal cutoff value determined during validation using ACMG guidelines. The detection cutoff for both dual-color, dual-fusion probes (IGH/BCL2 and IGH/BCL1) was greater than 1 cell in at least 50 non-overlapping cells observed, and the detection cutoff for the BCL2 dual-color break-apart probe was greater than 4 cells in at least 50 nonoverlapping cells observed.

\section{Molecular}

In cases 1 and 2, PCR testing for the myeloid differentiation primary response 88 gene (MYD88) mutation was performed. DNA was extracted and analyzed by PCR and a quantitative pyrosequencing method for the presence of a mutation at codon 265 of MYD88. The mutation detected in codon 265, exon 5 (CTG to CCG) of MYD88 that would change the encoded amino acid from leucine to proline (p. Leu265Pro). Sequencing was performed using the MYD 88 reference sequence NM_007562, and the lower limit of detection for the assay was $5-10 \%$ mutation-bearing cells in the sample tested.

\section{Results}

\section{Morphology}

The lymph node from case 1 was enlarged $(1.8 \times 0.6 \times 0.5 \mathrm{~cm})$. The capsule was thickened with significant capsular infiltration and focal extracapsular extension of lymphoid tissue identified. Sinuses were patent with some focal sinus histiocytosis. The normal nodal architecture was distorted. The interfollicular areas were markedly expanded. They consisted of a mixture of small lymphocytes, plasmacytoid lymphocytes, and plasma cells (Fig. 1). Rare larger transformed lymphocytes were seen. Very rare Dutcher bodies were identified in plasma cells. There were some residual germinal centers identified. Most of these had a typical appearance, with polarization, tingible body macrophages, and varied cytology. Two small follicles lacked tingible body macrophages and polarization and had a relatively monotonous cytologic composition.

The lymph node from case 2 was also markedly enlarged $(2.0 \times 1.7 \times 0.8 \mathrm{~cm})$. The capsule was thickened with significant capsular infiltration, and extensive extracapsular extension of lymphoid tissue into perinodal adipose tissue was identified. Many patent sinuses with sinus histiocytosis were seen. The normal nodal architecture was maintained but distorted. Interfollicular areas were replaced by a population of small lymphocytes, plasmacytoid lymphocytes, and plasma cells with rare, large transformed lymphocytes (Fig. 2). Rare plasma cells with Dutcher bodies or Russell bodies were seen. There were some residual germinal centers. Additionally, large amounts of tattoo pigment (mostly black, rare green/ blue) were noted within macrophages, associated with areas of paracortical hyperplasia and perivascular hyalinization (Table 2).

The lymph node from case 3 was similarly markedly enlarged $(2.4 \times 1.2 \times 1.2 \mathrm{~cm})$. The lymph node capsule was thin with no significant capsular infiltration or extracapsular extension of lymphoid tissue identified. Patent sinuses were identified. The lymph node architecture was predominantly nodular in pattern. Most of the nodules present were uniform in cytologic composition. In the uniform nodules, the lymphocytes were predominantly small in size with slightly irregular nuclei, dense chromatin, and scant cytoplasm (Fig. 3). Only rare germinal centers were identified at the periphery of the lymph node. In the germinal centers, the lymphocytes were more varied in appearance with some larger, transformed lymphocytes with admixed smaller lymphocytes. A few small foci of paracortical hyperplasia were noted.

\section{Immunophenotype}

Immunohistochemistry demonstrated interfollicular expansion in cases 1 and 2 by CD20+, BCL2+, CD5-, CD10small B cells admixed with numerous $\operatorname{IgM}+$, and kapparestricted plasma cells, consistent with lymphoplasmacytic lymphoma. In case 3, the nodular expansion was demonstrated to consist of $\mathrm{CD} 20+$, CD5+, cyclin $\mathrm{D} 1+$, SOX11+, and BCL2+ small B cells, consistent with mantle cell lymphoma (Fig. 3). In all three cases, a small subset $[2 / 25$ (8\%) of follicles in case $1 ; 9 / 38(24 \%)$ in case $2 ; 9 / 62$ (15\%) in case 3 ] of the germinal centers showed partial or complete strong positivity for BCL2 (Fig. 3); these same cells had expression of CD10 and BCL6, with intact follicular dendritic networks by CD23, consistent with follicular lymphoma in situ. The FLIS cells were negative for CD5, cyclin D1, and SOX11.

\section{FISH}

In case 1 , the $B C L 2$ break-apart probe was positive in the lymphoma. However, deeper tissue sections did not appear to contain the abnormal follicles, and no evidence of an $I G H /$ $B C L 2$ translocation was identified. It is possible that there was a $B C L 2 /$ kappa or lambda light chain translocation, but these probe sets were not available for testing. In case 2, FISH signals were too weak for accurate analysis. This was likely due to a technical artifact such as fixation or processing, and 
Fig. 1 Case 1. a-d Images of Waldenstrom macroglobulinemia/ lymphoplasmacytic lymphoma with follicular lymphoma in situ. Intermediate magnification of lymphoplasmacytic process involving lymph node (a). High magnification of interfollicular infiltrate consisting of lymphocytes, lymphoplasmacytic cells, and plasma cells (b; inset, Dutcher body).

Immunohistochemical staining for BCL2 showing strong abnormal staining in abnormal follicle of follicular lymphoma in situ in lower right (arrow)(c). Immunohistochemical staining for IgM (upper inset, kappa immunohistochemical staining; lower inset, lambda immunohistochemical staining)(d)

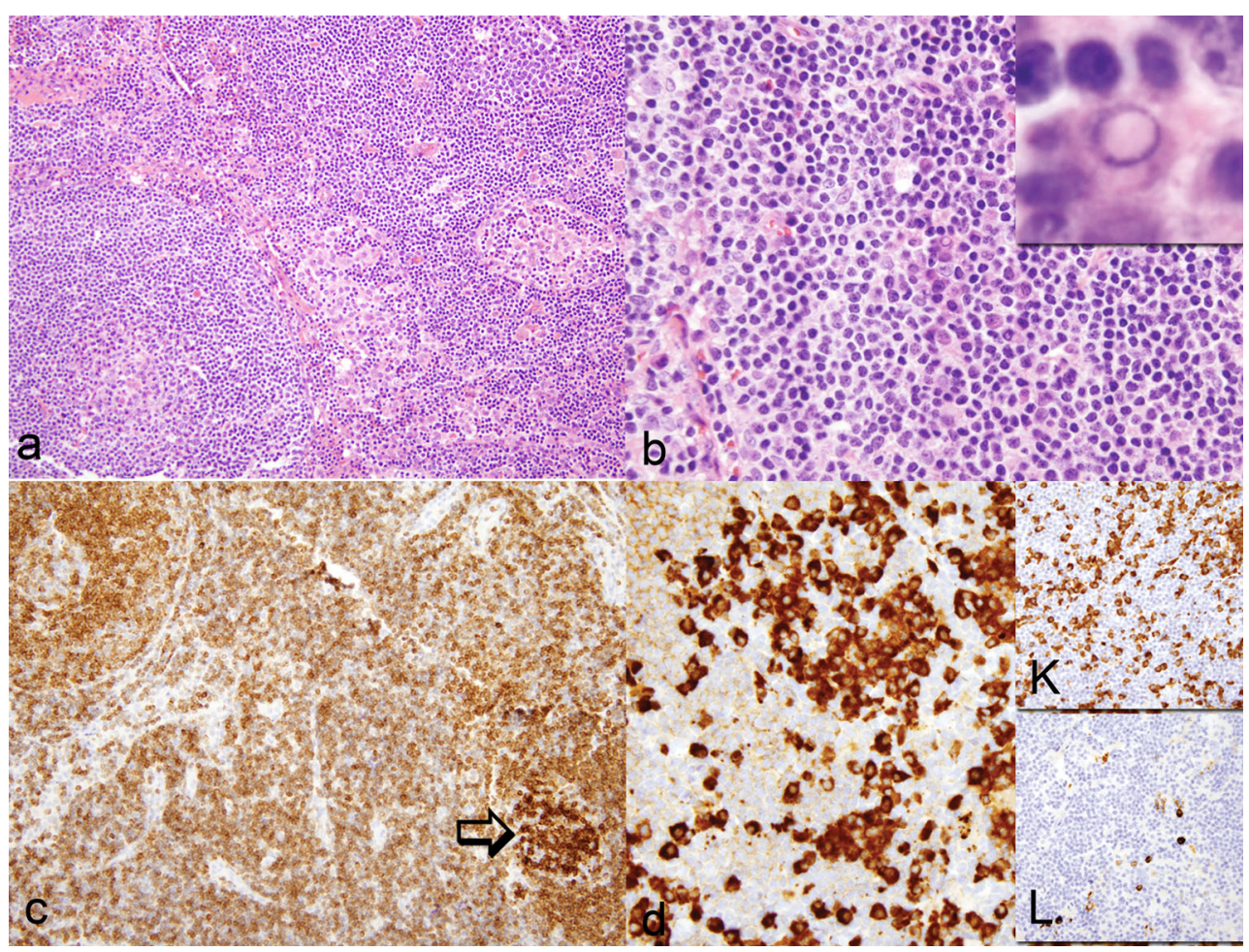

no result was obtained. Case 3 showed evidence of positive results for BCL2 break-apart probe and IGH/BCL1 (CCND1). The BCL2 and BCL1 breaks were present in different cells. Deeper sections did not contain areas of the abnormal follicles, and no abnormal signals suggesting translocation of $I G H / B C L 2$ were seen in remaining tissue.

\section{Molecular}

MYD 88 mutation was identified by PCR in the lymphoplasmacytic lymphoma in case 1 . No MYD88 mutation was identified in case 2 . Of note, case 2 did demonstrate bone marrow involvement.
Fig. 2 Case 2. a-d Images of Waldenstrom macroglobulinemia lymphoplasmacytic lymphoma with follicular lymphoma in situ. Low magnification of lymphoplasmacytic process involving lymph node, including areas of paracortical hyperplasia and normal and abnormal follicles (a). High magnification of interfollicular infiltrate consisting of lymphocytes, lymphoplasmacytic cells, and plasma cells (b; upper inset, Dutcher body, H\&E; low inset; Dutcher body, PAS). Immunohistochemical staining for BCL2 showing strong abnormal staining in abnormal follicle of follicular lymphoma in situ in lower right arrow; black staining is tattoo pigment(c). Immunohistochemical staining for IgM (upper inset, kappa immunohistochemical staining; lower inset, lambda

immunohistochemical staining)(d)

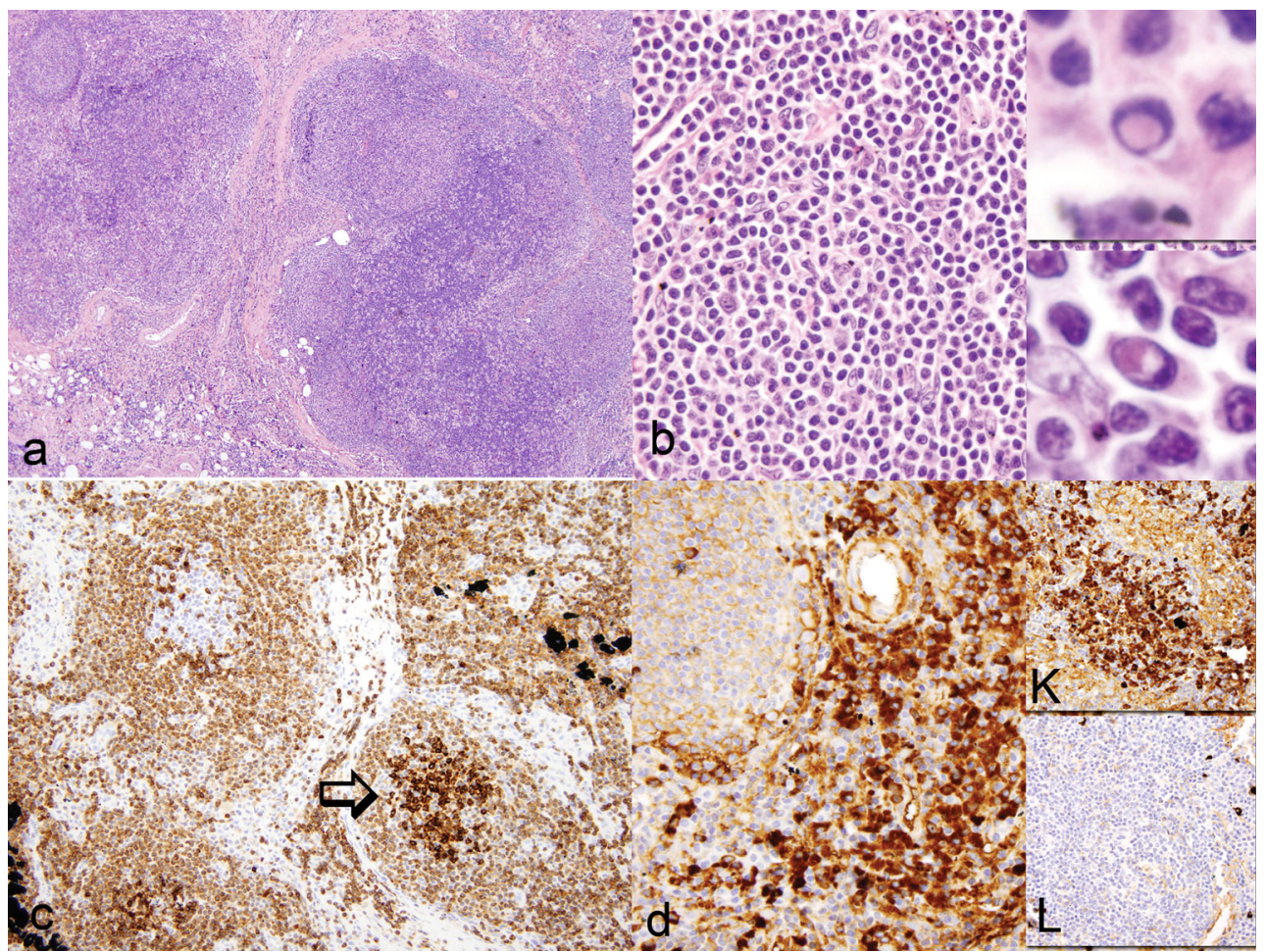


Table 2 Summary of results of cases with concurrent follicular lymphoma in situ

\begin{tabular}{llll}
\hline Result & Case 1 & Case 2 & Case 3 \\
\hline Diagnosis & LPL & LPL & Mantle cell lymphoma \\
$B C L 2$ break-apart FISH & + & $\mathrm{NR}$ & + \\
$I G H / B C L 2$ FISH in FLIS & $\mathrm{NR}$ & $\mathrm{NR}$ & - \\
$I G H / B C L 1$ FISH & $\mathrm{ND}$ & $\mathrm{ND}$ & + \\
$M Y D 88$ by PCR & + & - & $\mathrm{ND}$ \\
\hline
\end{tabular}

$L P L$ lymphoplasmacytic lymphoma, $N R$ no result, $N D$ not performed

\section{Discussion}

Our case series adds to the accumulation of data regarding FLIS, a relatively recently defined entity, with an incidence of $2-2.6 \%[3,19]$. It is defined as the presence within a lymph node of a subset of aberrantly BCL2 protein-positive follicles with the $\mathrm{t}(14 ; 18)$ ( $\mathrm{q} 32 ; \mathrm{q} 21) I G H / B C L 2$ translocation characteristic of follicular lymphoma. The lymphoma cells, however, are confined within the follicles without disruption of normal architecture and also otherwise demonstrate benign cytologic features. Our understanding of the natural evolution of FLIS is nascent. The majority of FLIS are not associated with any other pathologic conditions [3, 4, 27]. When present, FLIS is most frequently associated with synchronous or metachronous overt follicular lymphoma $[3,4,10]$.

However, interestingly, FLIS has also been reported in association with other B cell lymphoproliferative disorders. These cases include chronic lymphocytic leukemia/small lymphocytic lymphoma (three cases) [3, 11, 28], lymphoplasmacytic lymphoma (one case) [3, 11], nodal marginal zone lymphoma (one case) [11], diffuse large B cell lymphoma (five cases) [4, 28], classical Hodgkin lymphoma (five cases) [4, 11, 28], splenic marginal zone lymphoma (two cases) [4], mantle cell lymphoma in situ (three cases) [8, 23, 28], overt mantle cell lymphoma (one case) [23], MALT lymphoma (one case) [28], peripheral T cell lymphoma (three case) $[24,28]$, and mycosis fungoides (one case) [28]. Our case series adds to the growing repertoire of cases in which FLIS is found in association with a second, overt, and different B cell lymphoproliferative disorder. Interestingly, some studies have suggested that the amount of infiltration of the lymph node by FLIS appears to directly correlate with the probability of both overt follicular lymphoma as well as other lymphoma subtypes, raising speculations that FLIS may be a marker for
Fig. 3 Case 3. a-e Mantle cell lymphoma with follicular lymphoma in situ. Low magnification H\&E image of lymphoma with a nodular and diffuse pattern; small follicles are seen (a). High magnification of follicle with CD5 staining in mantle zone (b) and expression of cyclin D1 (c) and SOX11 (d), confirming the diagnosis of mantle cell lymphoma. Image of BCL2 immunohistochemical stain showing strong abnormal staining in follicular lymphoma in situ, moderate positivity in mantle cell lymphoma, and no staining in small residual follicle (lower right)(e)

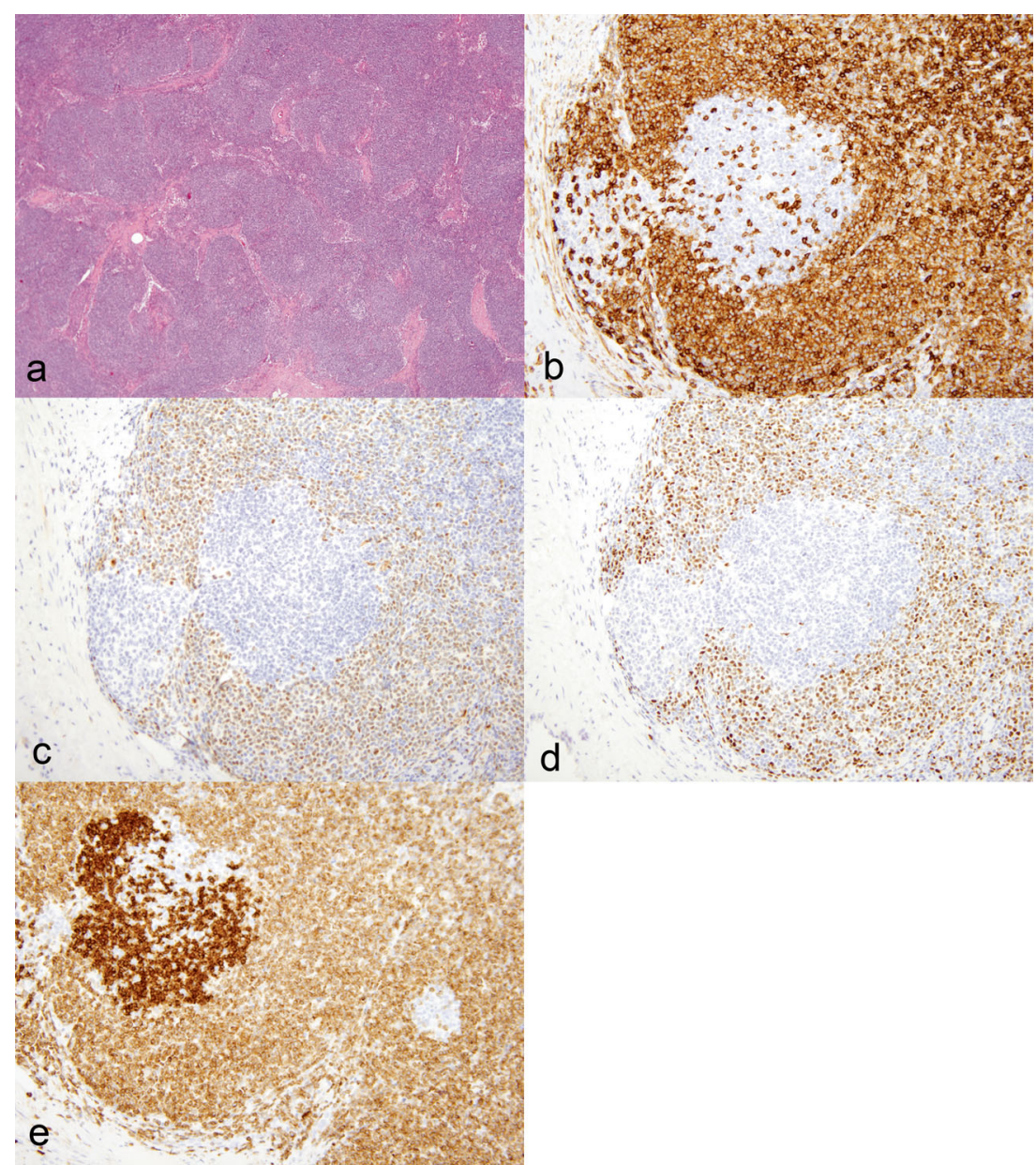


increased tendency to develop lymphoid malignancies due to underlying molecular abnormalities [3, 4], though these conclusions have been challenged by results from other studies showing that the extent of involvement by FLIS was not associated with an increased likelihood of overt lymphoma [28]. Alternatively, it is also possible that FLIS appears frequently along with another lymphoma simply because it is a relatively common incidental finding.

Our case series also raises the issue of the clonal relationship in low-grade composite B cell lymphomas. Composite lymphomas are defined as the presence of two or more morphologically and immunophenotypically distinct lymphomas in the same tissue or organ. An area of interest and active debate surrounds the clonal relationship in composite lymphomas.

Some data in the literature appear to suggest that when two or more distinct lymphomas are present in the same tissue, they may be clonally related. For example, Tsang et al. microdissected a composite follicular and mantle cell lymphoma and demonstrated a dominant rearranged IgH band identical in size via PCR, which on subsequent cloning and sequence analysis revealed a common clone-specific $I G H$ gene rearrangement, suggesting evolution from a common clone [7]. Wang et al. microdissected two cases of composite grade $1 \mathrm{FL}$ with accompanying in situ mantle cell lymphoma (MCL), and immunoglobulin heavy chain fragment length analysis showed identical dominant monoclonal peaks in the FL and in situ MCL components [13]. Carbone et al. demonstrated a common clonal origin for a composite follicular and mantle cell lymphoma using immunomagnetic sorting and gene rearrangement studies [25]. Similarly, Roullet et al. analyzed a composite follicular and mantle cell lymphoma and demonstrated a shared monoclonal IGK@ rearrangement [8].

However, subsequent analysis of IGH@ PCR by Roullet et al. demonstrated monoclonality in the mantle cell lymphoma only as well as mutually exclusive BCL2 and BCL1 $(C C N D 1)$ translocations in the follicular and mantle cell lymphoma, respectively, thereby providing seemingly conflicting data regarding the clonal relationship of the two different lymphomas [8]. In other studies, Fend et al. separated the components of composite mantle/follicular, follicular/small lymphocytic, and mantle/small lymphocytic lymphomas using laser capture microdissection and demonstrated two unrelated clones at the IGH FR3 locus in the different components, supporting separate clonal processes [5]. Similarly, Zamò et al. analyzed a composite mantle cell and follicular lymphoma using manual and laser capture microdissection, heavy and light chain recombination, VK/kappa-deleting element recombination, and sequence analysis and demonstrated two distinct, clonally unrelated populations [6]. However, it has been noted that the heavy, ongoing somatic hypermutations of IGH@ in follicular lymphoma may contribute to a failure to detect clonality and confound studies attempting to establish clonal relationship within composite lymphomas[9].

The coexistence of FLIS with another low-grade B cell lymphoma, both in our case series as well as the literature, suggests these disparate processes may arise via transdifferentiation in some cases. It is conceivable that an initial physiologic event (IgH rearrangement) occurs and secondary events (such as $I G H / B C L 2$ or $I G H / B C L 1$ translocation or MYD88 mutation) result in divergent clonal evolution and phenotype. However, as the tissue, in particular the FLIS component, was exhausted on deeper sections, we were not able to perform molecular studies of microdissected regions to explore the clonal relationship of the composite lymphomas in this case series.

Certainly, our understanding of the relatively recently described entity of FLIS as well as the relationship between composite lymphomas is still growing, and continued accumulation of cases and data will help us better understand the nature of both FLIS as well composite lymphomas.

Conflict of interest Drs. O'Malley, Grimm, Hummel, and Weiss are employees of Clarient Diagnostic Services. There is no declared COI from this relationship.

\section{References}

1. Carbone A, Gloghini A, Santoro A (2012) In situ follicular lymphoma: pathologic characteristics and diagnostic features. Hematol Oncol 30:1-7

2. Carbone A, Gloghini A (2013) Emerging issues after the recognition of in situ follicular lymphoma. Leuk Lymphoma [Epub ahead of print]

3. Cong P, Raffeld M, Teruya-Feldstein J, Sorbara L, Pittaluga S, Jaffe ES (2002) In situ localization of follicular lymphoma: description and analysis by laser capture microdissection. Blood 99:3376-3382

4. Montes-Moreno S, Castro Y, Rodríguez-Pinilla SM, García JF, Mollejo M, Castillo ME, Bas-Vernal A, Barrionuevo-Cornejo C, Sanchez-Verde L, Menarguez J, Cigudosa JC, Piris MA (2010) Intrafollicular neoplasia/in situ follicular lymphoma: review of a series of 13 cases. Histopathology 56:658-662

5. Fend F, Quintanilla-Martinez L, Kumar S, Beaty MW, Blum L, Sorbara L, Jaffe ES, Raffeld M (1999) Composite low grade B-cell lymphomas with two immunophenotypically distinct cell populations are true biclonal lymphomas. A molecular analysis using laser capture microdissection. Am J Pathol 154:1857-1866

6. Zamò A, Zanotti R, Lestani M, Ott G, Katzenberger T, Scarpa A, Pizzolo G, Menestrina F, Chilosi M (2006) Molecular characterization of composite mantle cell and follicular lymphoma. Virchows Arch 448:639-643

7. Tsang P, Pan L, Cesarman E, Tepler J, Knowles DM (1999) A distinctive composite lymphoma consisting of clonally related mantle cell lymphoma and follicle center cell lymphoma. Hum Pathol 30: 988-992

8. Roullet MR, Martinez D, Ma L, Fowler MH, McPhail ED, Judkins A, Arber DA, Bagg A (2010) Coexisting follicular and mantle cell lymphoma with each having an in situ component: a novel, curious, 
and complex consultation case of coincidental, composite, colonizing lymphoma. Am J Clin Pathol 133:584-591

9. Ilgenfritz RB, Le Tourneau A, Arborio M, Molina TJ, Diebold J, Damotte D, Audouin J (2009) Composite mantle cell and follicular lymphoma. A case report. Hum Pathol 40:259-263

10. Torlakovic E, Torlakovic G (2002) Follicular colonization by follicular lymphoma. Arch Pathol Lab Med 126:1136-1137

11. Jegalian AG, Eberle FC, Pack SD, Mirvis M, Raffeld M, Pittaluga S, Jaffe ES (2011) Follicular lymphoma in situ: clinical implications and comparisons with partial involvement by follicular lymphoma. Blood 118:2976-2984

12. Limpens J, Stad R, Vos C, de Vlaam C, de Jong D, van Ommen GJ, Schuuring E, Kluin PM (1995) Lymphoma-associated translocation $\mathrm{t}(14 ; 18)$ in blood B cells of normal individuals. Blood 85:2528-2536

13. Wang S, Tzankov A, Xu-Monette ZY, Hoeller S, Wang SA, Richards KL, Zhang S, Said JW, Medeiros LJ, Young KH (2013) Clonally related composite follicular lymphoma and mantle cell lymphoma with clinicopathologic features and biological implications. Hum Pathol 44:2658-2667

14. Rabkin CS, Ct H, Janz S, Dolken G $(2008) \mathrm{t}(14 ; 18)$ translocations and risk of follicular lymphoma. J Natl Cancer Inst Monogr 2008:4851

15. Roulland S, Lebailly P, Lecluse Y, Heutte N, Nadel B, Gauduchon P (2006) Long-term clonal persistence and evolution of $\mathrm{t}(14 ; 18)$-bearing B cells in healthy individuals. Leukemia 20:158-162

16. Roulland S, Lebailly P, Lecluse Y, Briand M, Pottier D, Gauduchon P (2004) Characterization of the $\mathrm{t}(14 ; 18)$ BCL2-IGH translocation in farmers occupationally exposed to pesticides. Cancer Res 64:2264 2269

17. Schuler F, Hirt C, Dolken G (2003) Chromosomal translocation $\mathrm{t}(14 ; 18)$ in healthy individuals. Semin Cancer Biol 13:203-209

18. Dolken G, Illerhaus G, Hirt C, Mertelsmann R (1996) BCL-2/JH rearrangements in circulating $\mathrm{B}$ cells of healthy blood donors and patients with nonmalignant diseases. J Clin Oncol 14:1333-1344

19. Henopp T, Quintanilla-Martinez L, Fend F, Adam P (2011) Prevalence of follicular lymphoma in situ in consecutively analysed reactive lymph nodes. Histopathology 59:139-142
20. Bonzheim I, Salaverria I, Haake A, Gastl G, Adam P, Siebert R, Fend F, Quintanilla-Martinez L (2011) A unique case of follicular lymphoma provides insights to the clonal evolution from follicular lymphoma in situ to manifest follicular lymphoma. Blood 118:3442-3444

21. Adam P, Katzenberger T, Eifert M, Ott MM, Rosenwald A, MüllerHermelink HK, Ott G (2005) Presence of preserved reactive germinal centers in follicular lymphoma is a strong histopathologic indicator of limited disease stage. Am J Surg Pathol 29:1661-1664

22. Carvajal-Cuenca A, Campo E (2013) Early neoplastic lymphoid lesions. Sem Diag Pathol 30:146-155

23. Carbone A, Gloghini A (2011) Coexisting follicular and mantle cell lymphoma with each having an in situ component. Am J Clin Pathol 136:481-483

24. Carbone A, Della Libera D, Zannier L, Selva A, Ceolin P, Gualeni A, Canal B, Gloghini A (2011) In situ follicular lymphoma associated with overt B- or T-cell lymphomas in the same lymph node. Am J Hematol 86:E66-E70

25. Carbone A, Gloghini A, Volpe R, Attadia V, Gattei V, Zagonel V, Pinto A (1992) Follicular lymphoma of compartmentalized small cleaved center cells and mantle zone lymphocytes: evidence for a common derivation. Am J Clin Pathol 98:437-448

26. Mamessier E, Song JY, Eberle FC, Pack S, Drevet C, Chetaille B, Abdullaev Z, Adelaïde J, Birnbaum D, Chaffanet M, Pittaluga S, Roulland S, Chott A, Jaffe ES, Nadel B (2013) Early lesions of follicular lymphoma: a genetic perspective. Haematologica [Epub ahead of print]

27. Fend F, Cabecadas J, Gaulard P, Jaffe ES, Kluin P, Kuzu I, Peterson L, Wotherspoon A, Sundström C (2012) Early lesions in lymphoid neoplasia: conclusions based on the Workshop of the XV. Meeting of the European Association of Hematopathology and the Society of Hematopathology, in Uppsala, Sweden. J Hematop 5:169-199

28. Pillai RK, Surti U, Swerdlow SH (2013) Follicular lymphoma-like B cells of uncertain significance (in situ follicular lymphoma) may infrequently progress, but precedes follicular lymphoma, is associated with other overt lymphomas and mimics follicular lymphoma in flow cytometric studies. Haematologica 98:1571-1580 